\title{
Genome-wide association study of Striga resistance in early maturing white tropical maize inbred lines
}

Samuel Adeyemi Adewale 1,2, Baffour Badu-Apraku*, Richard Olutayo Akinwale², Agre Angelot Paterne, Melaku Gedil ${ }^{1}$ and Ana Luísa Garcia-Oliveira ${ }^{1}$

\begin{abstract}
Background: Striga hermonthica (Benth.) parasitism militates against increased maize production and productivity in savannas of sub-Saharan Africa (SSA). Identification of Striga resistance genes is important in developing genotypes with durable resistance. So far, there is only one report on the existence of QTL for Striga resistance on chromosome 6 of maize. The objective of this study was to identify genomic regions significantly associated with grain yield and other agronomic traits under artificial Striga field infestation. A panel of 132 early-maturing maize inbreds were phenotyped for key agronomic traits under Striga-infested and Striga-free conditions. The inbred lines were also genotyped using 47,440 DArTseq markers from which 7224 markers were retained for population structure analysis and genome-wide association study (GWAS).
\end{abstract}

Results: The inbred lines were grouped into two major clusters based on structure analysis as well as the neighborjoining hierarchical clustering. A total of 24 SNPs significantly associated with grain yield, Striga damage at 8 and 10 weeks after planting (WAP), ears per plant and ear aspect under Striga infestation were detected. Under Striga-free conditions, 11 SNPs significantly associated with grain yield, number of ears per plant and ear aspect were identified. Three markers physically located close to the putative genes GRMZM2G164743 (bin 10.05), GRMZM2G060216 (bin 3.06) and GRMZM2G103085 (bin 5.07) were detected, linked to grain yield, Striga damage at 8 and 10 WAP and number of ears per plant under Striga infestation, explaining 9 to $42 \%$ of the phenotypic variance. Furthermore, the S9_154,978,426 locus on chromosome 9 was found at $2.61 \mathrm{Mb}$ close to the ZmCCD1 gene known to be associated with the reduction of strigolactone production in the maize roots.

Conclusions: Presented in this study is the first report of the identification of significant loci on chromosomes 9 and 10 of maize that are closely linked to ZmCCD1 and amt5 genes, respectively and may be related to plant defense mechanisms against Striga parasitism. After validation, the identified loci could be targets for breeders for marker-assisted selection (MAS) to accelerate genetic enhancement of maize for Striga resistance in the tropics, particularly in SSA, where the parasitic weed is endemic.

Keywords: DArTseq markers, Genome-wide association study, Marker-assisted selection, Striga hermonthica, Striga resistance, Zea mays $\mathrm{L}$

\footnotetext{
*Correspondence: b.badu-apraku@cigar.org; b.badu-apraku@cgiar.org

${ }^{1}$ International Institute of Tropical Agriculture (IITA), PMB 5320, Oyo Road, Ibadan, Nigeria

Full list of author information is available at the end of the article
}

(c) The Author(s). 2020 Open Access This article is licensed under a Creative Commons Attribution 4.0 International License, which permits use, sharing, adaptation, distribution and reproduction in any medium or format, as long as you give appropriate credit to the original author(s) and the source, provide a link to the Creative Commons licence, and indicate if changes were made. The images or other third party material in this article are included in the article's Creative Commons licence, unless indicated otherwise in a credit line to the material. If material is not included in the article's Creative Commons licence and your intended use is not permitted by statutory regulation or exceeds the permitted use, you will need to obtain permission directly from the copyright holder. To view a copy of this licence, visit http://creativecommons.org/licenses/by/4.0/ The Creative Commons Public Domain Dedication waiver (http://creativecommons.org/publicdomain/zero/1.0/) applies to the data made available in this article, unless otherwise stated in a credit line to the data. 


\section{Background}

Striga hermonthica is a parasitic weed causing remarkable reduction in maize yield in the SSA and threatens the livelihoods of more than 300 million people [1]. Striga infestation is most severe in areas with low soil fertility, low rainfall and farming systems characterized by poor crop management practices and little use of inputs such as fertilizer, pesticides, and improved seeds [2]. Yield losses attributable to Striga parasitism range from 20 to $80 \%$ and the levels of infestation are often so high that maize may suffer $100 \%$ yield loss, and farmers could be forced to abandon their fields [3-6].

Striga seeds germinate in response to strigolactones in the root exudates of maize plants. Germinated seeds develop haustoria which attach to the roots of the host plants through which photosynthates and nutrients are transferred from the maize to the Striga plant [1]. Once attached to maize roots, the Striga plants survive by siphoning-off water and nutrients from the host plant for its own growth and development. The development of Striga plants impairs the normal host-plant growth, resulting in a large reduction in plant height, biomass, and eventually grain yield [7]. Feasible control options include intercropping, rotation of cereals with crops that are not susceptible to $S$. hermonthica such as cotton (Gossypium spp), soybean (Glycine max L.), and cowpea (Vigna unguiculata L.), herbicide treatment, handpulling, use of catch and trap crops, high nitrogen fertilization and use of tolerant and resistant varieties [1]. Among these options, host plant resistance is the most economical, sustainable and environmentally friendly.

During the past two decades, the maize improvement program of the International Institute of Tropical Agriculture (MIP-IITA) has placed a major emphasis on the development of stable and durable resistance to Striga from the wild maize (Zea diploperennis L.) and African landraces. Through these efforts, several populations, inbred lines and hybrids with durable Striga resistance have been developed. For example, the early-maturing Striga resistant and drought-tolerant maize inbred line, TZdEI 352, derived from a cross between the normal endosperm white maize population TZEW Pop DT STR and the $Z$. diploperennis, has displayed increased grain yield and durable Striga resistance [8]. Akaogu et al. [8] reported dominance gene effects to be higher than the additive effects for the number of emerged Striga plants in TZdEI 352, implying that non-additive gene action conditioned inheritance of Striga resistance. This inbred TZdEI 352 and other inbreds including TZEI 1203, TZEI 1252, and TZEI 1348, have been reported to possess significant positive/negative general combining ability (GCA) effects for grain yield, Striga damage, number of emerged Striga plants, ears per plant and ear aspect.
The present focus of the IITA-MIP is to transfer novel Striga resistance genes into Striga susceptible but outstanding genotypes, through gene stacking. This will allow the development of inbreds, hybrids and other available maize germplasm with durable resistance and increased maize production and productivity in SSA. With the advent of rapid genome-wide high-density marker data using high-throughput and next-generation sequencing technologies, GWAS has become a common tool for identifying resistance genes and/or loci through genome-wide association mapping $[9,10]$. Identified genes and/or loci, once validated, could be fixed to provide maize germplasm with durable Striga resistance in tropical maize.

Information on the identification of QTL for Striga resistance in maize is very limited. Amusan [11] mapped two putative QTL on chromosome 6 of maize, from an $\mathrm{F}_{2}$ mapping population involving a cross between the Striga susceptible inbred line, 5057 and the resistant inbred line ZD05. These two QTL accounted for 55\% of the phenotypic variability with dominant effects overlapping in importance. Unlike maize, the progress in the identification of QTL for marker assisted selection in sorghum is more advanced. The identification of lg gene mutant alleles at the LGS1 (Low Germination Stimulant 1) locus on chromosome 5 of sorghum has reduced greatly the Striga hermonthica germination stimulant activity [12]. This gene was found to code for a sulfotransferase enzyme, and when silenced led to a change of 5-deoxystrigol into orobanchol compounds in the root exudates [12]. In addition, other loci have been reported to play important roles in parasitic resistance, including the genes $C C D 1, C C D 7$ and $C C D 8[13,14]$. In maize, roots with mycorrhizal formations have shown a higher ZmCCD1 expression and induced lower germination of Striga [13]. Liu et al. [15] provided evidence for strigolactones and strigolactone perception genes of the MAX-2-type in Striga hermonthica, namely ShCCD7 and ShCCD8. In tobacco, the silencing of CCD7 and CCD8 genes retarded the virus parasite formation in the host, indicating that these two genes are key in parasitic life cycle [14].

In Striga resistance breeding, the primary traits of interest in selecting for resistance and high grain yield are host plant damage, number of emerged Striga plants, ears per plant and ear aspect [1, 16-18]. The host plant damage is positively correlated with the number of emerged Striga plants, and the two traits are negatively correlated with yield. Therefore, there is need to identify the genomic regions and genes that control the inheritance of grain yield and closely associated traits for successful use of MAS in maize improvement under Striga field infestation. Identification of genomic regions for Striga resistance would therefore facilitate rapid and 
efficient transfer of resistance genes to susceptible maize genotypes. The objectives of this study were to i) determine the genetic structure of a panel of 132 diverse early maturing white maize inbred lines with varying levels of resistance to Striga hermonthica parasitism and ii) identify putative genes associated with grain yield and other Striga adaptive traits under Striga-infested and Strigafree environments, using GWAS.

\section{Results}

\section{Evaluation of phenotypic traits}

Analysis of variance (ANOVA) across Striga infested environments revealed significant genotype $(G)$ and environment (E) mean squares for all measured traits except environment mean squares for grain yield and Striga damage at 8 WAP (Table 1). Significant G x E mean squares were observed for ears per plant and number of emerged Striga plants at 8 and 10 WAP. Broad sense heritability $\left(\mathrm{H}^{2}\right)$ estimates under artificial Striga infestation ranged from $47 \%$ for number of emerged Striga plants at $10 \mathrm{WAP}$ to $71 \%$ for Striga damage at $10 \mathrm{WAP}$. Moderately high heritability estimates $\geq 60 \%$ were recorded for the Striga resistance indicator traits (grain yield, ears per plant, ear aspect, Striga damage at 8 and 10 WAP, and number of emerged Striga plants at 8 WAP) under Striga infestation. Under Striga-free conditions, the combined ANOVA displayed significant G, E and $G \times$ E mean squares for grain yield, ears per plant and ear aspect. Broad sense heritability estimates ranged from $28 \%$ for ears per plant to $58 \%$ for ear aspect when Striga-free.

The phenotypic correlations among grain yield and other measured Striga adaptive traits differed under artificial Striga infestation (Fig. 1). Grain yield had significant negative correlation with ear aspect $\left(r=-0.83^{* *}\right)$, Striga damage at 8 WAP $\left(r=-0.75^{* *}\right)$ and $10 \mathrm{WAP}(r=$ $\left.-0.74^{* *}\right)$, number of emerged Striga plants at 8 WAP $\left(r=-0.22^{*}\right)$ and 10 WAP $\left(r=-0.24^{* *}\right)$, and significant positive correlation with ears per plant $\left(r=0.41^{* * *}\right)$. Similarly, significant positive correlations were obtained between Striga damage at 8 WAP and Striga damage at 10 WAP $\left(r=0.84^{* *}\right)$, number of emerged Striga plants at 8 WAP and number of emerged Striga plants at 10 WAP $\left(r=0.90^{* *}\right)$, ear aspect and Striga damage $\left(r=0.71^{* * *}\right)$.

\section{Population structure and genetic diversity}

A total of 47,440 SNPs were generated for the maize inbred lines using DArT sequencing technology. After quality filtering of the unmapped and multilocation markers, SNPs with missing values $>10 \%$, heterozygosity $>20 \%$ and $\mathrm{MAF}<5 \%$ were excluded and thus, a total of 7224 SNPs were retained for the analysis (Additional file 1: Figure S1). The results of the summary statistics of the maize inbred lines based on the filtered

Table 1 Mean squares from the analysis of variance of grain yield and other agronomic traits of 132 tropical early maturing maize inbred lines evaluated under Striga-infested and Striga-free environments, at Mokwa between 2017 and 2018

\begin{tabular}{|c|c|c|c|c|c|c|c|c|}
\hline $\begin{array}{l}\text { Source of } \\
\text { variation }\end{array}$ & Df & $\begin{array}{l}\text { Yield, kg/ } \\
\text { ha }\end{array}$ & $\begin{array}{l}\text { Ears per } \\
\text { plant }\end{array}$ & $\begin{array}{l}\text { Ear } \\
\text { aspect }\end{array}$ & $\begin{array}{l}\text { Striga damage rating } \\
\text { at } 8 \text { WAP }\end{array}$ & $\begin{array}{l}\text { Striga damage rating } \\
\text { at } 10 \text { WAP }\end{array}$ & $\begin{array}{l}\text { Emerged Striga } \\
\text { plants at } 8 \text { WAP }\end{array}$ & $\begin{array}{l}\text { Emerged Striga plants } \\
\text { at } 10 \text { WAP }\end{array}$ \\
\hline \multicolumn{9}{|c|}{ Striga-infested conditions } \\
\hline $\begin{array}{l}\text { Environment } \\
\text { (E) }\end{array}$ & 1 & $1,041,553$ & $4.32^{* *}$ & $11.49^{* *}$ & 0.29 & $44.16^{* *}$ & $12.81^{* *}$ & $19.58^{* *}$ \\
\hline Block (Rep*E) & 44 & $493501^{*}$ & 0.03 & 1.23 & 0.98 & $1.17^{*}$ & 0.15 & 0.09 \\
\hline $\operatorname{Rep}(E)$ & 2 & $1117085^{*}$ & 0.04 & $3.64^{*}$ & 0.36 & 0.58 & $0.66^{* *}$ & 0.10 \\
\hline Genotype (G) & 131 & $846079^{* *}$ & $0.05^{* *}$ & $2.24^{* *}$ & $2.08^{* *}$ & $2.65^{* *}$ & $0.34^{* *}$ & $0.26^{* *}$ \\
\hline Env ${ }^{*}$ Genotype & 131 & 320,753 & $0.05^{* *}$ & 0.92 & 0.71 & 0.84 & $0.14^{*}$ & $0.15^{* *}$ \\
\hline Error & 218 & 323,545 & 0.02 & 0.97 & 0.70 & 0.73 & 0.11 & 0.09 \\
\hline Heritability & & 0.63 & 0.61 & 0.60 & 0.67 & 0.71 & 0.60 & 0.47 \\
\hline \multicolumn{9}{|c|}{ Striga-free conditions } \\
\hline $\begin{array}{l}\text { Environment } \\
\text { (E) }\end{array}$ & 1 & $1484892^{*}$ & $4.13^{* *}$ & $120.27^{* *}$ & & & & \\
\hline Block (Rep*E) & 44 & 352,004 & 0.06 & 0.83 & & & & \\
\hline $\operatorname{Rep}(E)$ & 2 & $3428522^{* *}$ & $0.35^{* *}$ & $5.38^{* *}$ & & & & \\
\hline Genotype (G) & 131 & $1059290^{* *}$ & $0.15^{* *}$ & $3.10^{* *}$ & & & & \\
\hline $\begin{array}{l}\text { Env* } \\
\text { Genotype }\end{array}$ & 131 & $495955^{* *}$ & $0.10^{* *}$ & $1.28^{* *}$ & & & & \\
\hline Error & 218 & 347,667 & 0.07 & 0.73 & & & & \\
\hline Heritability & & 0.54 & 0.28 & 0.58 & & & & \\
\hline
\end{tabular}




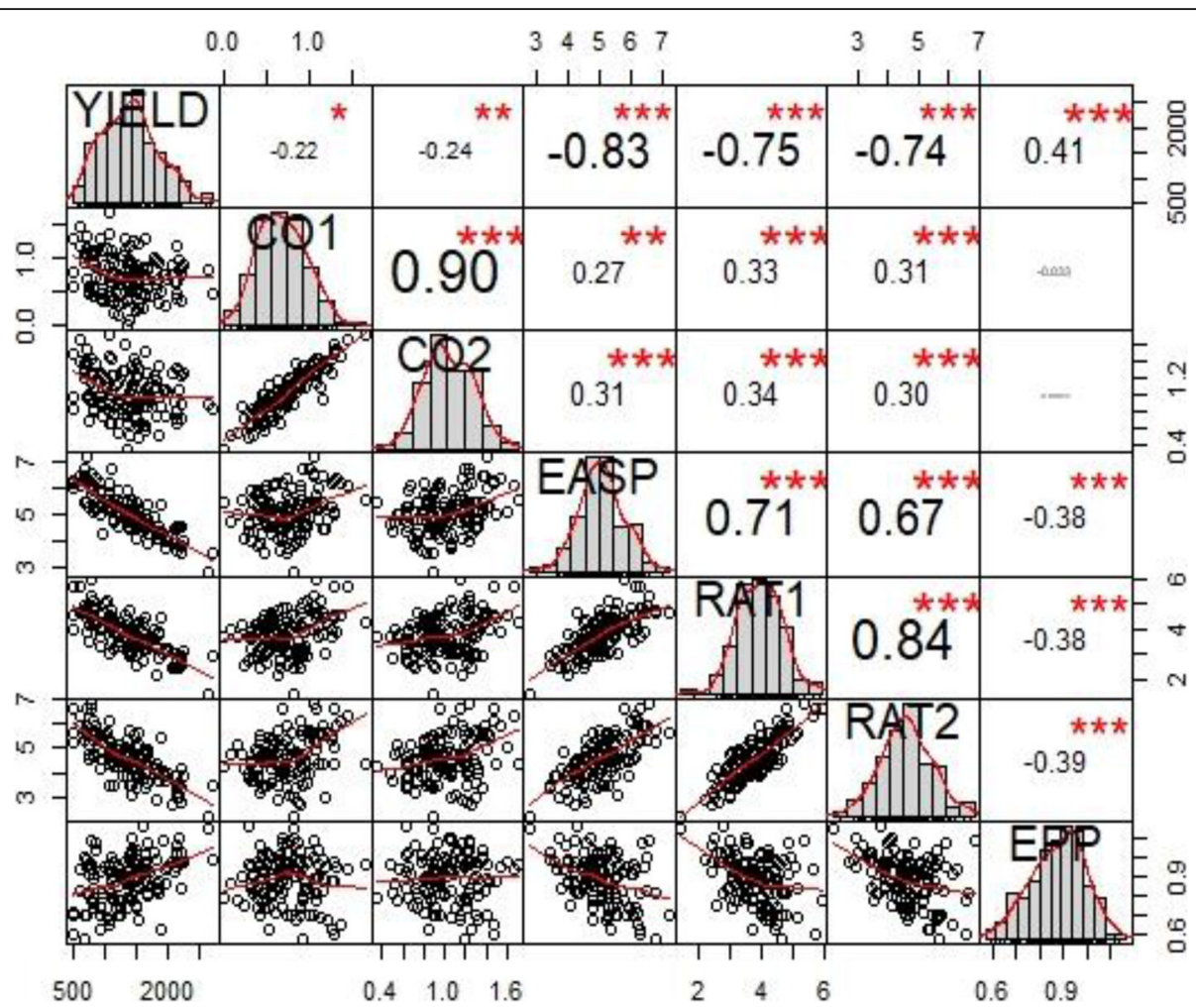

Fig. 1 Correlation coefficients between Striga resistance indicator traits and other agronomic traits of early maturing maize inbred lines under artificial Striga infestation at Mokwa between 2017 and 2018. YIELD = grain yield, CO1 = number of emerged Striga plants at 8 WAP, CO2 = number of emerged Striga plants at 10 WAP, EASP - ear aspect, RAT1 = Striga damage symptoms rating at 8 WAP, RAT2 - Striga damage symptoms rating at 10 WAP, EPP - number of ears per plant

7224 markers are displayed in Additional file 2: Table S1. The PIC ranged from 0.09 to 0.37 with an average of 0.26 whereas the heterozygosity averaged 0.07 and varied from 0.00 to 0.20 . The minor allele frequencies of the 7224 primers recorded a mean of 0.24 with minimum and maximum minor allele frequencies of 0.05 and 0.5 , respectively. Gene diversity varied from 0.10 to 0.50 with an average of 0.33 .

Population structure was inferred through the admixture model-based clustering method [19]. The STRUCT URE algorithm and STRUCTURE HARVESTER results revealed delta $\mathrm{K}$ plot peak value of two (Fig. 2b). The results of the unweighted neighbor joining phylogenetic tree, color coded from the STRUCTURE results, also indicated two major groups (Fig. 2a). At $\mathrm{k}=2,89 \%$ of the inbred lines were assigned into two groups, and only $11 \%$ of the lines were assigned in the mixed group. A total of 45 inbred lines were placed in group 1, 72 in group 2 and 15 in the mixed group. Each group comprised inbred lines from two or more germplasm sources. Of the 45 inbred lines placed in group 1, 26 were derived from the biparental crosses (TZE COMP 5-W DT C7 x TZEI 56, TZE COMP 5-W DT C7 x TZEI 65, TZE COMP 5-W DT C7 x TZEI 18), 8 were obtained from TZE COMP 5-W DT C7 x TZEI 31 while 6 were extracted from TZE COMP 5-W DT C7 x TZEI 87, TZE COMP 5-W DT C7 x TZEI 2. Furthermore, the inbred testers TZEI 1 and TZEI 18 (derived from population TZE-W Pop STR Co) as well as TZEI 7, TZEI 31 and TZdEI 352 (derived from WEC STR S7, TZE-W Pop x LD and TZE-W Pop STR 107, respectively), were also classified into group 1 . Of the 72 inbred lines classified into group 2, 36 were derived from the biparental crosses (TZE COMP 5-W DT C7 x TZEI 56, TZE COMP 5-W DT C7 x TZEI 65, TZE COMP 5-W DT C7 $x$ TZEI 18), 28 derived from TZE COMP 5-W DT C7 $x$ TZEI 87, TZE COMP 5-W DT C7 x TZEI 2 and 7 from TZE COMP 5-W DT C7 x TZEI 31. In addition, the inbred tester TZEI 19 developed from TZE-W Pop STR Co was placed in group 2. The inbred lines placed in the two groups had in common the broad based Striga resistant population TZE COMP 5-W DT C7. However, the grouping of the inbred lines was largely based on the reactions of the inbred lines to Striga as each group contained both resistant and susceptible inbred lines. Using the IITA selection base index, 38 of the 45 inbred lines placed in group 1 were Striga resistant while 7 were susceptible (Table not shown). In 


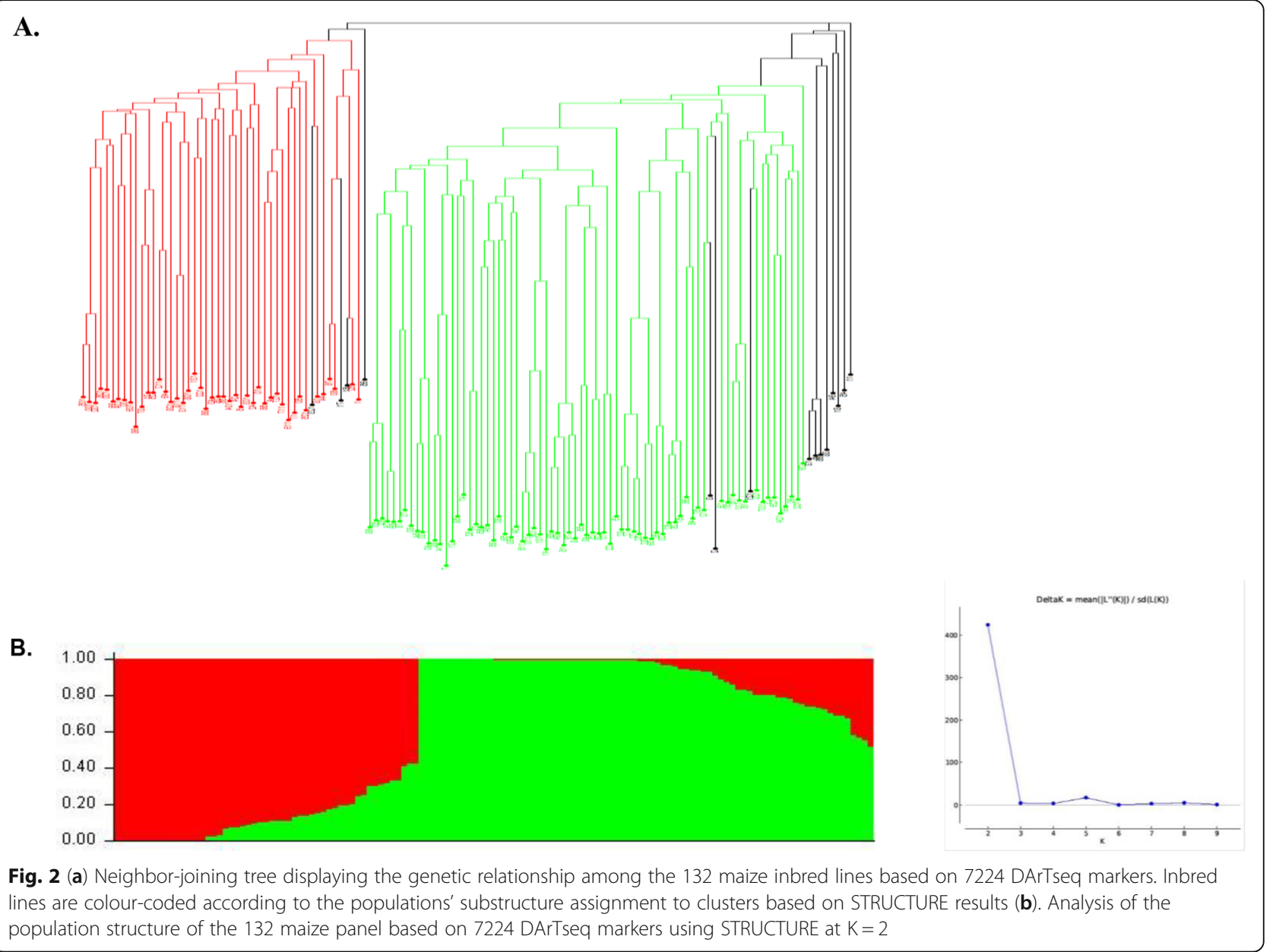

contrast, out of 72 inbred lines placed in group 2, there were 52 each of Striga resistant and 20 susceptible inbreds. It is interesting that the grouping of most of the inbred testers was largely based on resistance to Striga. For example, the Striga resistant inbred testers TZdEI 352, TZEI 7 and TZEI 1 , the moderately resistant testers TZEI 18, and susceptible tester TZEI 31 were placed in group 1 while the Striga susceptible inbred tester TZEI 19 was placed in group 2 .

\section{Population linkage disequilibrium (LD)}

Linkage disequilibrium analysis revealed the presence of 359,926 loci pairs within a physical distance extending up to $55,266,364 \mathrm{bp}$. About $22.05 \%(79,364)$ of the loci pairs were in significant LD $(P<0.001)$. In addition, $1231(0.30 \%)$ of the loci pairs were in complete LD $\left(\mathrm{R}^{2}=1\right)$. Pearson's correlation coefficients showed negative and significant correlation $(r=-0.035)$ between the linkage disequilibrium $\left(\mathrm{R}^{2}\right)$ and the physical distance (bp) as well as between the $P$-value and $\mathrm{R}^{2}(r=-0.59)$, indicating the existence of linkage decay. The rate of $\mathrm{LD}$
Table 2 Details of LD decay distance observed at $R^{2}<0.2$ on the different chromosomes and the entire maize genome

\begin{tabular}{llll}
\hline Chromosome & Size $(\mathrm{Mb})$ & Mean $\mathrm{r}^{2}$ & LD decay distance $(\mathrm{Kb})$ at $\mathrm{r}^{2}<0.2$ \\
\hline 1 & 167.12 & 0.04 & 6971.163 \\
2 & 117.22 & 0.04 & 7178.097 \\
3 & 140.09 & 0.03 & 7531.945 \\
4 & 141.96 & 0.03 & 8212.815 \\
5 & 105.37 & 0.04 & 6947.642 \\
6 & 110.94 & 0.04 & 7893.009 \\
7 & 113.14 & 0.03 & 7921.105 \\
8 & 113.19 & 0.03 & 7923.937 \\
9 & 95.80 & 0.03 & 7412.867 \\
10 & 91.09 & 0.03 & 8367.483 \\
Whole genome & 123.45 & 0.40 & 7542.275 \\
Average & 119.59 & 0.03 & 7636.006 \\
\hline
\end{tabular}


decay differed across the chromosomes (Additional file 3: Figure S2), ranging from $6948 \mathrm{~kb}$ for chromosome 5 to $8367 \mathrm{~kb}$ for chromosome 10 at $\mathrm{r}^{2}<0.2$ (Table 2). The average pairwise $r^{2}$ and LD decay at $r^{2}<0.2$ for the entire genome was approximately 0.03 and $7636 \mathrm{~kb}$, respectively. The slowest LD decay was observed for chromosome $10(8367 \mathrm{~kb})$, followed by chromosome 4 $(8213 \mathrm{~kb})$ and chromosome $8(7924 \mathrm{~kb})$.

\section{Genome-wide association and LD analysis}

Under artificial Striga infestation, 24 significant SNPs were detected for five different traits at a GWAS

Table 3 DArTseq markers having significant association with Striga-adaptive traits of 132 inbred lines evaluated under Striga-infested and Striga-free conditions at Mokwa across years 2017 and 2018

\begin{tabular}{|c|c|c|c|c|c|}
\hline Trait & SNP & Chr & Position & P-value & Marker $\mathrm{R}^{2}$ \\
\hline \multicolumn{6}{|l|}{ Striga-infested conditions } \\
\hline \multirow[t]{3}{*}{ Grain yield } & S10_96,965,850 & 10 & $96,965,850$ & $4.95 \times 10^{-4}$ & 0.343 \\
\hline & S9_7,249,203 & 9 & $7,249,203$ & $5.25 \times 10^{-4}$ & 0.342 \\
\hline & S10_133,224,759 & 10 & $133,224,759$ & $8.43 \times 10^{-4}$ & 0.336 \\
\hline \multirow[t]{7}{*}{ Ears per plant } & S5_207,493,972 & 5 & $207,493,972$ & $1.04 \times 10^{-4}$ & 0.130 \\
\hline & S7_137,739,978 & 7 & $137,739,978$ & $1.21 \times 10^{-4}$ & 0.127 \\
\hline & S10_16,561,232 & 10 & $16,561,232$ & $2.16 \times 10^{-4}$ & 0.118 \\
\hline & S7_140,475,074 & 7 & $140,475,074$ & $6.08 \times 10^{-4}$ & 0.101 \\
\hline & S10_16,804,228 & 10 & $16,804,228$ & $8.98 \times 10^{-4}$ & 0.095 \\
\hline & S5_215,584,703 & 5 & $215,584,703$ & $9.44 \times 10^{-4}$ & 0.094 \\
\hline & S4_76,136,186 & 4 & $76,136,186$ & $9.81 \times 10^{-4}$ & 0.094 \\
\hline \multirow[t]{5}{*}{ Striga damage at 8 WAP } & S10_133,224,759 & 10 & $133,224,759$ & $4.41 \times 10^{-5}$ & 0.420 \\
\hline & S7_79,624,222 & 7 & $79,624,222$ & $5.14 \times 10^{-4}$ & 0.393 \\
\hline & S8_52,394,249 & 8 & $52,394,249$ & $5.94 \times 10^{-4}$ & 0.391 \\
\hline & S10_112,661,466 & 10 & $112,661,466$ & $8.01 \times 10^{-4}$ & 0.388 \\
\hline & S3_179,448,461 & 3 & $179,448,461$ & $9.91 \times 10^{-4}$ & 0.385 \\
\hline \multirow[t]{7}{*}{ Striga damage at 10 WAP } & S10_133,224,759 & 10 & $133,224,759$ & $3.55 \times 10^{-5}$ & 0.333 \\
\hline & S10_112,661,466 & 10 & $112,661,466$ & $1.88 \times 10^{-4}$ & 0.311 \\
\hline & S3_179,448,461 & 3 & $179,448,461$ & $2.61 \times 10^{-4}$ & 0.307 \\
\hline & S1_9,730,753 & 1 & $9,730,753$ & $3.75 \times 10^{-4}$ & 0.303 \\
\hline & S3_47,343,213 & 3 & $47,343,213$ & $4.32 \times 10^{-4}$ & 0.301 \\
\hline & S3_143,135,181 & 3 & $143,135,181$ & $4.60 \times 10^{-4}$ & 0.300 \\
\hline & S9_154,978,426 & 9 & $154,978,426$ & $8.99 \times 10^{-4}$ & 0.292 \\
\hline Striga count at 8 WAP & S1_102,219,766 & 1 & $102,219,766$ & $3.42 \times 10^{-4}$ & 0.221 \\
\hline Ear aspect & S10_144,129,548 & 10 & $144,129,548$ & $5.94 \times 10^{-4}$ & 0.258 \\
\hline \multicolumn{6}{|l|}{ Striga-free conditions } \\
\hline \multirow[t]{2}{*}{ Grain yield } & S4_177,968,538 & 4 & $177,968,538$ & $8.09 \times 10^{-4}$ & 0.148 \\
\hline & S3_188,682,443 & 3 & $188,682,443$ & $9.12 \times 10^{-4}$ & 0.141 \\
\hline \multirow[t]{4}{*}{ Ears per plant } & S2_210,201,646 & 2 & $210,201,646$ & $6.86 \times 10^{-4}$ & 0.143 \\
\hline & S8_145,372,017 & 8 & $145,372,017$ & $7.55 \times 10^{-4}$ & 0.132 \\
\hline & S1_67,606,758 & 1 & $67,606,758$ & $8.57 \times 10^{-4}$ & 0.130 \\
\hline & S1_68,549,674 & 1 & $68,549,674$ & $9.07 \times 10^{-4}$ & 0.129 \\
\hline \multirow[t]{5}{*}{ Ear aspect } & S8_96,677,591 & 8 & $96,677,591$ & $4.00 \times 10^{-4}$ & 0.207 \\
\hline & S6_97,507,107 & 6 & $97,507,107$ & $5.74 \times 10^{-4}$ & 0.235 \\
\hline & S3_176,205,016 & 3 & $176,205,016$ & $5.57 \times 10^{-4}$ & 0.203 \\
\hline & S8_161,625,705 & 8 & $161,625,705$ & $6.00 \times 10^{-4}$ & 0.201 \\
\hline & S6_108,391,162 & 6 & $108,391,162$ & $9.98 \times 10^{-4}$ & 0.194 \\
\hline
\end{tabular}


threshold of $-\log (\mathrm{p})=4$ (Table 3$)$. The trait variation explained by each marker $R^{2}$ varied from 9 to $42 \%$. Of the 24 SNPs that were significant, nine were located on chromosome 10. Three markers located on chromosomes 10 and 9 were associated with grain yield and explained about $34 \%$ of the phenotypic variation. Ears per plant was associated with seven markers located on chromosomes 4, 5, 7, and 10. These markers revealed 9 to $13 \%$ of the phenotypic variation. Ear aspect had only one significant SNP located on chromosome 10 under Striga-infestation. Furthermore, five SNPs located on chromosomes 3, 7, 8 and 10 were detected for Strigadamage at 8 WAP, 7 SNPs on chromosomes 1, 3, 9 and 10 for Striga-damage at $10 \mathrm{WAP}$ and one SNP on chromosome 1 for number of emerged Striga plants at 8 WAP. The marker S10_133,224,759 explained the highest proportion of the phenotypic variance $(42 \%)$ while S5_215,584,703 and S4_76,136,186 explained the least proportion $(9 \%)$ of the phenotypic variation. Marker S10_133,224,759 located on chromosome 10 was found associated repeatedly with grain yield and Striga damage at 8 and 10 WAP. Similarly, marker S10_112,661,466 on chromosome 10 was found to be common for Striga damage at 8 and 10 WAP.

Under Striga-free conditions, 11 SNPs significantly associated with grain yield, ears per plant and ear aspect were detected (threshold of $-\log (\mathrm{p})=4$ ), accounting for
13 to $23 \%$ of the total phenotypic variation observed among the traits. Two markers located on chromosomes 3 and 4 were associated with grain yield and explained 14 to $15 \%$ of the phenotypic variation in grain yield. Number of ears per plant had four significant SNPs situated on chromosomes 8, 2 and 1 explaining 13 to $21 \%$ of the phenotypic variation. In addition, five different SNPs located on chromosomes 3, 6 and 8 were associated with ear aspect, describing 19 to $24 \%$ of the phenotypic variation. Significant SNPs identified for grain yield, ears per plant and ear aspect under Striga-infestation were different from those under Striga-free conditions. The results of the SNPs for grain yield, ears per plant and Striga damage under Striga infestation are illustrated in the Manhattan and quantile-quantile plots (Figs. 3 and 4). The quantile-quantile plots revealed good data adjustment and a few significant SNPs above the interval for the expected values of the null hypothesis. LD block heatmaps of the three candidate gene loci identified are shown in Fig. 5. LD analysis of each of the three loci revealed that these markers had relatively low LD parameter $\left(R^{2}\right)$, indicating relatively low correlation with each other.

\section{Candidate loci for Striga hermonthica resistance}

The genomic regions of the significant SNPs were examined to identify the protein-coding genes located in or

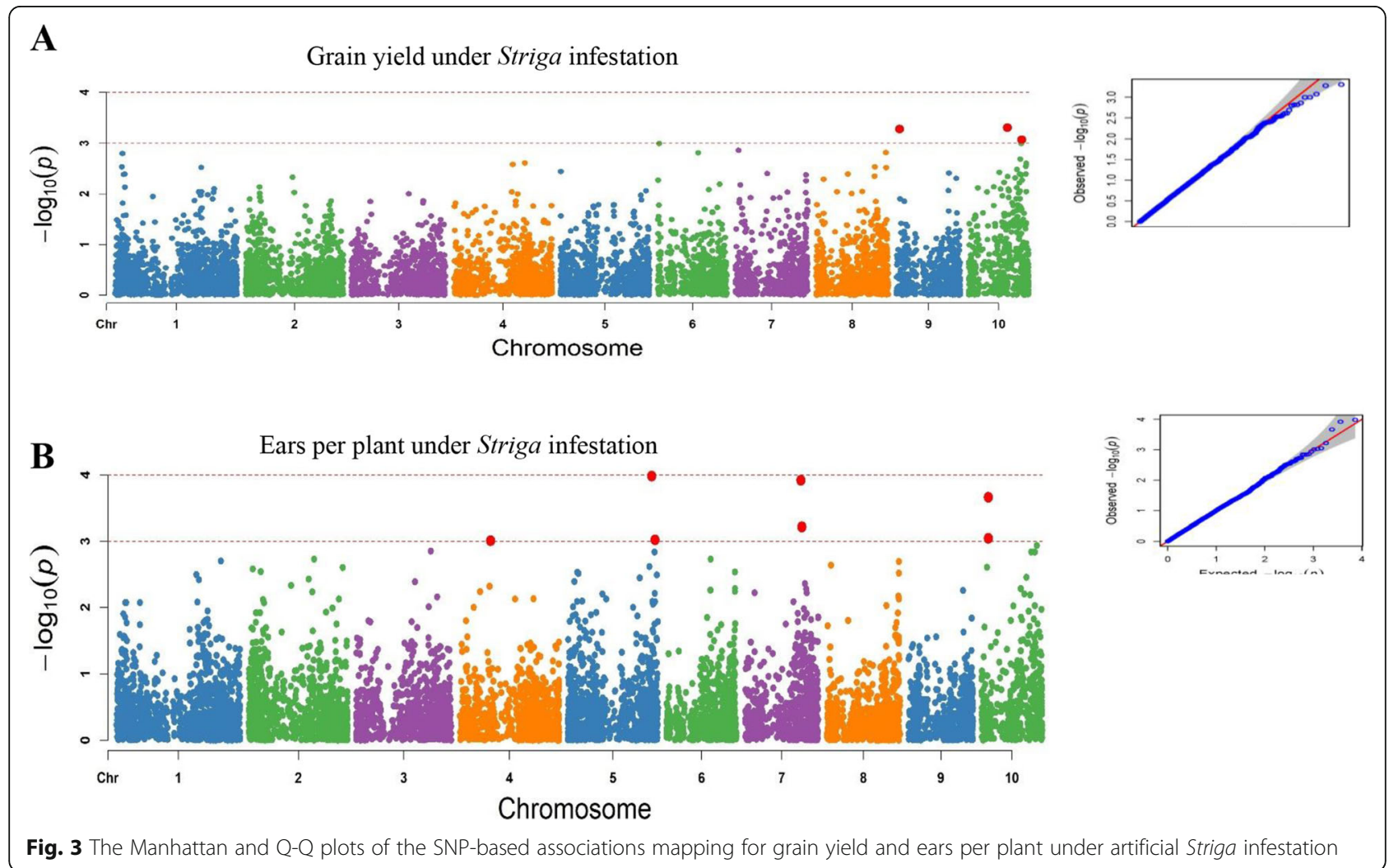




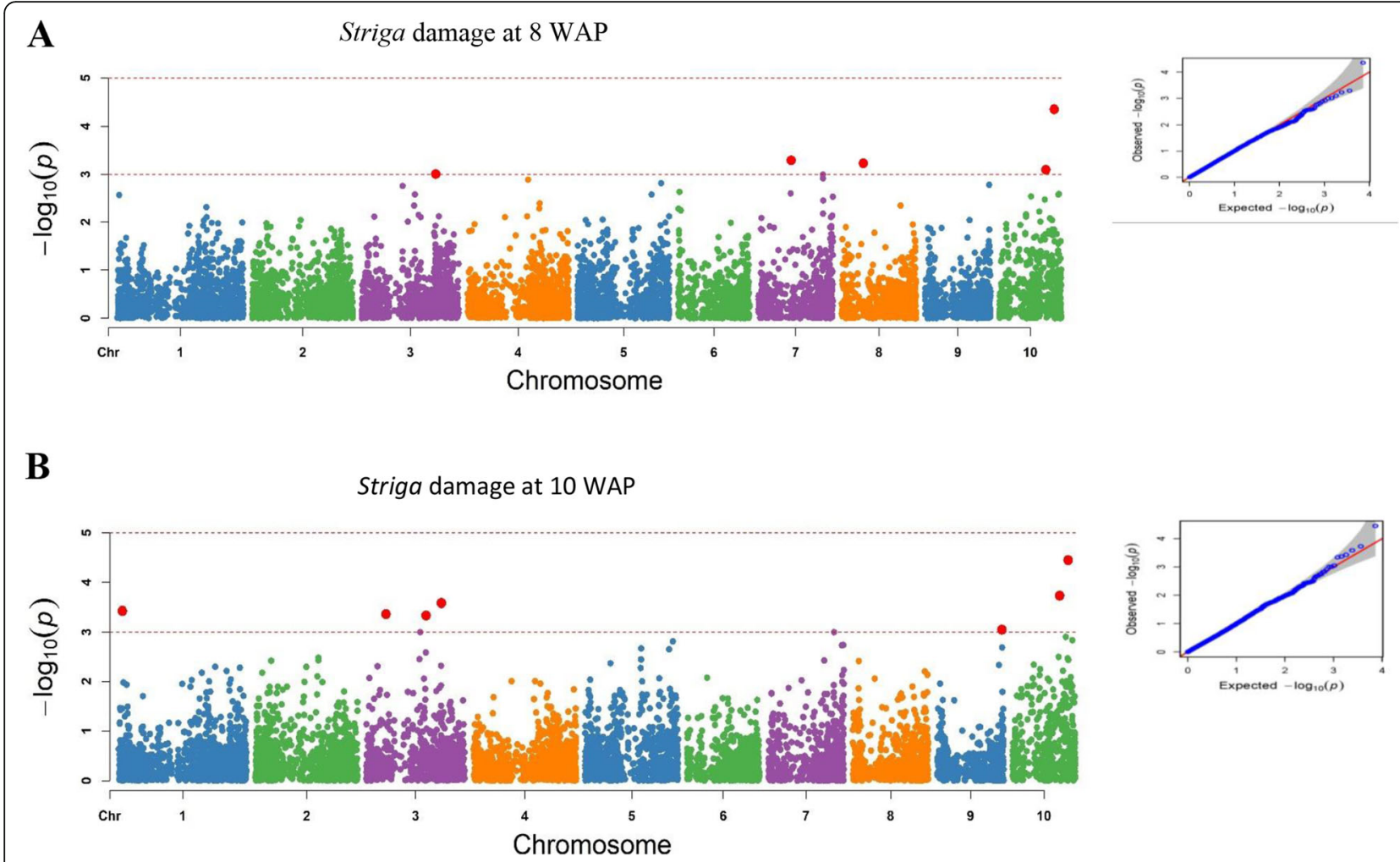

Fig. 4 The Manhattan and Q-Q plots of the SNP-based associations mapping for Striga damage at 8 WAP and 10 WAP under artificial Striga infestation

Chromosome 10

Physical Length:859kb

A

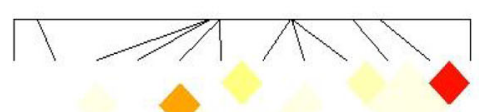

Chromosome 5

C

IPy
Chromosome 3

Physical Length: $8663.3 \mathrm{~kb}$

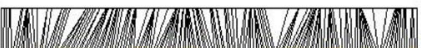

Fig. 5 Local LD block surrounding (a) amt5 gene on chromosome 10. (b) ereb13 gene on chromosome 3 . (c) lg2 gene on chromosome 3 . The square lattice panel represents the extent of LD based on $r^{2}$. The $\mathrm{R}^{2}$ color key indicates the degree of significant association 
Table 4 Candidate genes for each significant SNP associated with Striga adaptive traits under Striga infestation and Striga-free conditions

\begin{tabular}{|c|c|c|c|c|}
\hline Trait & Chr & Position & Gene ID & Encoding products \\
\hline \multicolumn{5}{|l|}{ Striga-infested conditions } \\
\hline $\begin{array}{l}\text { Grain yield and Striga } \\
\text { damage }\end{array}$ & 10 & $\begin{array}{l}133,224 \\
759\end{array}$ & GRMZM2G164743 & amt5 (ammonium transporter protein) \\
\hline Grain yield & 9 & $7,249,203$ & $\begin{array}{l}\text { GRMZM2G080044, } \\
\text { GRMZM5G898880 }\end{array}$ & $\begin{array}{l}\text { Cellular respiration, oxidative phosphorylation, alternative NAD (P) H } \\
\text { dehydrogenase activities. }\end{array}$ \\
\hline \multirow[t]{3}{*}{ Striga damage } & 9 & $\begin{array}{l}154,978 \\
426\end{array}$ & GRMZM2G057243 & ZmCCD1 gene \\
\hline & & & GRMZM2G010017 & Protein phosphatase $2 \mathrm{C}$ family protein \\
\hline & 3 & $\begin{array}{l}179,448 \\
461\end{array}$ & GRMZM2G060216 & lg2 (basic leucine zipper protein transcription factor) \\
\hline \multirow[t]{4}{*}{ Ears per plant } & 10 & $\begin{array}{l}16,561 \\
232\end{array}$ & GRMZM2G310674 & Polynucleotidyl transferase, ribonuclease $\mathrm{H}$-like superfamily protein \\
\hline & 7 & $\begin{array}{l}137,739 \\
978\end{array}$ & GRMZM2G016836 & NAD (P)-binding Rossmann-fold superfamily protein \\
\hline & 5 & $\begin{array}{l}207,493 \\
972\end{array}$ & GRMZM2G315127 & Plant protein of unknown function \\
\hline & 5 & $\begin{array}{l}215,584 \\
703\end{array}$ & EREB139, GRMZM2G103085 & AP2-EREBP (ethylene-responsive element-binding proteins) \\
\hline \multicolumn{5}{|l|}{ Striga-free conditions } \\
\hline \multirow[t]{3}{*}{ Ears per plant } & 2 & $\begin{array}{l}210,201 \\
646\end{array}$ & $\begin{array}{l}\text { GRMZM2G009412, } \\
\text { GRMZM2G125527 }\end{array}$ & Zinc-binding ribosomal protein family protein \\
\hline & 1 & $\begin{array}{l}67,606 \\
758\end{array}$ & GRMZM2G078806 & Putative uncharacterized protein \\
\hline & 1 & $\begin{array}{l}68,549 \\
674\end{array}$ & GRMZM2G125314 & LOL3 (protein degradation) \\
\hline Ear aspect & 8 & $\begin{array}{l}96,677, \\
591\end{array}$ & GRMZM2G083344 & Glucose-6-phosphate/phosphate translocator-related \\
\hline
\end{tabular}

close to the significant SNPs based on the data retrieved from the maize genetic database (http://www.maizegdb. $\operatorname{org} /)$. The list of annotated genes, including those encoding uncharacterized proteins of the most significant SNPs are presented in Table 4. The SNP S10_133,224, 759 having significant association with grain yield and Striga damage under Striga infestation was located within the candidate gene amt5 (ammonium transporter 5) with identifier GRMZM2G164743. Similarly, SNP S10_16,561,232 having strong association with ears per plant under Striga infestation was located on another candidate gene GRMZM2G310674, which encodes a Polynucleotidyl transferase putative protein, belonging to the ribonuclease H-like superfamily protein. On chromosome 9, SNP S9_7,249,203 associated with grain yield under Striga infestation was physically located within the putative genes GRMZM2G080044 and GRMZM5G898880. These genes are responsible for cellular respiration, oxidative phosphorylation and NAD (P) $\mathrm{H}$ dehydrogenase activities. Additionally, SNP S9_154, 978,426 significantly associated with Striga damage was located on the protein-coding putative gene
GRMZM2G010017 that encodes a protein phosphatase $2 \mathrm{C}$ family protein and $2.62 \mathrm{Mb}$ close to the $\mathrm{Zmccd} 1$ gene, GRMZM2G057243. On chromosome 5, S5_207, 493,972 and S5_215,584,703 associated with ears per plant under Striga infestation were located on the GRMZM2G315127 and $131.43 \mathrm{~kb}$ close to GRMZM2G103085 putative genes, respectively. The putative gene GRMZM2G315127 encodes for an uncharacterized protein while the GRMZM2G103085/EREB139 putative gene encodes for ethylene-responsive elementbinding proteins. Marker S3_179,448,461 having significant association with Striga damage was found $60.7 \mathrm{~kb}$ close to the candidate gene lg2, GRMZM2G060216, which encodes a basic leucine zipper protein transcription factor. On chromosome 7, S7_137,739,978 having significant association with ears per plant under Striga infestation was located on the putative gene GRMZM2G016836, which encodes the NAD (P)-binding Rossmann-fold superfamily protein.

Under Striga-free conditions, S1_67,606,758 and S1_ $68,549,674$ linked with ears per plant on chromosome 1 were found on the GRMZM2G078806 and 
GRMZM2G125314 putative genes, respectively. These genes encode for a putative uncharacterized protein and LOL3 (protein degradation), respectively. Similarly, SNP S2_210,201,646 on chromosome 2 associated with ears per plant was located on the putative genes GRMZM2G009412 and GRMZM2G125527. These genes encode for Zinc-binding ribosomal protein. SNP S8_96,677,591 significantly linked to ear aspect was found within the gene GRMZM2G083344, encoding glucose-6-phosphate/phosphate translocator-related proteins.

\section{Discussion}

The significant variation observed among the inbred lines for grain yield and other agronomic traits revealed the existence of adequate genetic variability among the early maturing maize inbred lines under Striga-infested and Striga-free research conditions. The significant environment mean squares observed for most traits in the present study showed the distinctness of the environments in discriminating among the genotypes under each research condition [20,21]. Moderate to high heritability estimates detected for grain yield and other Striga adaptive traits implied increased power of SNP detection in the maize panel allowing for identification of true associations between a marker and putative gene [22-24]. The significant positive correlation observed between grain yield and ears per plant and significant negative correlations between grain yield and Striga damage, number of emerged Striga plants and ear aspect suggested simultaneous improvement of these traits would result in high yield under Striga infestation. Previous studies identified grain yield, number of emerged Striga plants, Striga damage, ears per plant and ear aspect as the most reliable traits in selecting for Striga resistant maize genotypes, thus justifying their inclusion in the selection index for yield improvement in Striga-prone environments in SSA $[17,25]$.

Approximately $70 \%$ of the SNPs used in the study had heterozygosity $<5 \%$. The lower values of heterozygosity observed among the inbred lines in the two groups indicated that the SNPs were efficient in forming homogenous groups. Thus, making them a valuable resource for genetic studies and association mapping where uniformity of inbred lines and genetic divergence are required [26]. The average PIC value of $0.26 \mathrm{ob-}$ tained in this study is higher than that reported by Adu et al. [26] but comparable to those reported previously by Simko et al. [27] and Zhang et al. [28]. This reveals the informativeness of the markers used in this study. The frequency of minor alleles is a crucial factor influencing the accuracy of LD analysis and GWAS, especially when using small number of genotypes $[29,30]$. The filtered high-quality SNPs used in this study had a large proportion of MAFs distributed uniformly across the genome, frequencies greater than $5 \%$. Most of the significant SNPs identified in the present study had MAFs greater than $10 \%$, implying the positive detection power of the GWAS as the biasness associated with rare alleles was removed [31].

Estimation of population structure and within-group relatedness in maize genomic association studies is necessary in order to reduce the risk of false-positives [22, 32]. The 132 inbred lines used in this study were classified into two major clusters $(k=2)$ by the DArTseq markers and each cluster was further partitioned into sub-clusters. Results obtained from the population structure analysis were similar to those previously reported by Cui et al. [33] in sesame, Campa et al. [34] in common bean, Mogga et al. [35] in rice, Maldonado et al. [36] in maize. It is interesting that the grouping of the inbred lines by the markers was mostly based on the reactions of the inbred lines to Striga as each group contained both resistant and susceptible inbred lines. The results of the population structure analysis were confirmed by the neighbor joining phylogenetic tree. The average genome-wide LD decay was estimated at $7636 \mathrm{kbp}$ at $\mathrm{r}^{2}<0.2$. Previous studies reported LD less than $1000 \mathrm{bp}$ for maize landraces, about $100 \mathrm{~kb}$ for commercial elite breeding lines and about $830 \mathrm{Kbp}$ for diverse breeding lines [30, 37]. The existence of marker pairs in LD over long distances in the present study was expected since such large LD is a feature of advanced maize inbred lines that have gone through selection [30]. The large LD could lead to the identification of SNPs in genes that either cause or contribute to Striga resistance, or which act as linked markers associated with Striga resistance.

The model fitness for the GWAS was confirmed by inspecting quantile-quantile (QQ) plots that compared the observed and expected $p$-values under the null hypothesis of no associations. Our results revealed that majority of points in the QQ plots were aligned on the diagonal line for all the measured traits, indicating that spurious associations due to population structure and familial relatedness were largely corrected. Similar findings were reported by Kuki et al. [23], who identified genomic regions, including putative genes, associated with resistance to gray leaf spot disease in tropical maize under natural disease infection.

Marker-trait association analyses have demonstrated that association between specific phenotypes and genotypes within a genome, could lead to the discovery of genes controlling the traits [38]. In order to increase the level of resistance to Striga in the available early maturing tropical maize germplasm, 24 markers significantly associated with Striga damage, number of emerged Striga plants, number of ears per plant, ear aspect and 
grain yield under Striga infestation were identified, at the threshold of $-\log (p)=4$. These markers were located on chromosomes $10,9,8,7,5,4,3$ and 1 . In contrast to the present results, Amusan [11] identified two putative loci for resistance to Striga on chromosome 6 of maize, using SSR markers and composite interval mapping $(\mathrm{CIM})$ in a late maturing maize $\mathrm{F}_{2}$ mapping population. The first QTL was found between markers umc2170 and bnlg1142 whereas the second QTL was found between SSR markers bnlg1867 and umc1014 [11]. These loci were found to govern the incompatible response to Striga parasitism and accounted for $55 \%$ of the phenotypic variation (PV) with predominance of dominance genetic effects over additive genetic effects in the expression of the two Striga resistance QTLs [11]. In our present study, no significant loci were identified on chromosome 6 . The differences in the results of the two studies could be attributed to the differences in the genetic materials used in the two different studies. Furthermore, 11 markers were identified to be associated with grain yield, ears per plant and ear aspect under Strigafree conditions. These markers were located on chromosomes 8, 6, 4, 3 and 2. Lack of SNPs overlap for the measured traits under Striga infested and Striga-free environments indicated the genetic divergence between the two contrasting test environments. In addition, results of the present study showed that the Striga resistance indicator traits under artificial Striga-infested environments were complex in nature and were controlled by multiple minor QTLs with small effects distributed across the maize genome. The markers having significant association with Striga resistance indicator traits such as reduced Striga damage symptoms, increased number of ears per plant and high grain yield under Striga infestation could be used as candidate markers for simultaneous selection for the target traits in maize [1]. Allelic variations at each significant SNP were associated with 9 to $42 \%$ of the phenotypic variance, suggesting that these markers could be useful for marker-assisted selection for improved Striga resistance in tropical maize improvement programs. Striga resistance in maize is a polygenic trait making it relatively difficult to achieve good progress from selection. However, the identification of molecular markers tightly linked to functional genes is an important step towards development of genotypes with enhanced levels of resistance through gene pyramiding.

The most noticeable candidate genes identified in the present study are located at SNPs S9_154,978,426 and S10_133,224,759 on chromosomes 9 and 10, respectively. The SNP S9_154,978,426 is located at $2.62 \mathrm{Mb}$ from the $Z m C C D 1$ gene on chromosome 9 [13]. It has been shown that maize roots colonized by arbuscular mycorrhizal fungi had a higher $Z m C C D 1$ expression that could limit Striga germination [13]. This finding is particularly interesting as it is well known that the lowering of strigolactone production is still the best-known mechanism for preventing Striga germination [39, 40]). Since the $Z m C C D 1$ gene is involved in the formation of the yellow pigment apocarotenoids [13], it would be interesting in the future to understand the carotenoid levels of the lines and its relationship with Striga resistance in the maize inbred lines. On chromosome 10, the SNPs S10_133,224,759 and S10_112,661,466 are particularly interesting because they are significant for Striga damage at 8 and 10 WAP whereas S10_133,224,759 was significant for grain yield under Striga infestation. The SNP S10_133,224,759 located at the physical coordinates chr 10: 133,224,759 had the largest proportion of phenotypic variance $(46 \%)$ for Striga damage in the panel of the IITA early maturing maize inbred lines. This SNP marker is close to the functional gene GRMZM2G164743 (bin 10.05), which encodes an ammonium transporter protein (amt5). AMT genes have been identified in many plant species including Zea mays [41] and Sorghum bicolor [42]. Nitrate $\left(\mathrm{NO}^{-3}\right)$ and ammonium $\left(\mathrm{NH}^{+4}\right)$ are the major forms of nitrogen $(\mathrm{N})$ uptake in higher plants. The $\mathrm{NH}^{+4}$ ions accumulate in cells either by direct uptake from the rhizosphere via ammonium transporters (AMTs) or by reduction of $\mathrm{NO}^{-3}$. Dechorgnat et al. [43] found ZmAMT2.1 gene (a member of the AMT family) to be expressed in all organs with some specificity to roots and tassels. Interestingly, Koegel et al. [42] reported a similar expression pattern of the ZmAMT2.1 orthologue in sorghum. The authors observed that in sorghum, SbAMT2.1 was expressed in all organs studied with higher expression in roots and stamens. Nitrogen status of the plants is also closely associated with plant defense against Striga parasitism as several authors have reported significant reduction in number of emerged Striga plants under high nitrogen concentration [43, 44]. The SNP S10_133,224, 759 indicated that the candidate gene (amt5) identified in the present study could be responsible for the defense mechanism against Striga parasitism in maize. The gene therefore could be a novel target for further unravelling of the regulatory mechanism of Striga resistance in the roots of maize plants and should be tested further in breeding programs for its usefulness in selecting inbred lines with resistance to Striga hermonthica parasitism.

Marked association around lg2 gene was detected for Striga damage. The SNP S3_179,448,461, located at the long arm of chromosome 3 , was found close $(60.7 \mathrm{~kb})$ to the candidate gene GRMZM2G060216 (3.06), which is associated with loci $\lg 2$ (liguleless2). The $\lg 2$ gene encodes a basic leucine zipper protein transcription factor and has mutants known to affect leaf angle in maize. In maize, $\lg 1$ and $\lg 2$ mutants have no ligule or auricle, leading to considerably more upright leaves than their 
normal counterparts, thereby increasing photosynthetic activity and eventually leading to significant grain yield increase in maize hybrids [45]. Thus, the $\lg 2$ gene may be associated with maize plant defense mechanism under Striga infestation. Previous studies have revealed that Striga infection influences the rate of photosynthesis in the host plants' leaves by decreasing the effectiveness of the photosynthetic process. This has been demonstrated in sorghum, millet, cowpea as well as in maize $[7,46-50]$. The complex interplay between photosynthesis and plant defenses have been recently elucidated [51] and showed that both biological processes share common regulators. It would be interesting to further understand the contribution of the $\lg 2$ gene to host plant defense mechanisms under Striga infestation in the inbred lines studied.

The S5_215,584,703 is close $(131.43 \mathrm{~kb})$ to the gene "GRMZM2G103085-ereb13- AP2-EREBP”. EREBPs (also referred to as ethylene-responsive element-binding proteins) containing a single AP2 domain are involved in regulatory networks of response to hormones, pathogen attack, and environmental signals involving DREBs (dehydration responsive element binding proteins) and ERFs (ethylene responsive factors) [52, 53]. Interestingly, Li et al. [54] identified TaPARG-2A and TaPRG-2G in wheat, belonging to the AP2 subfamily of AP2/EREBP transcription factors, that are involved in regulation of diverse processes of plant development and stress response. Hirota et al. [55] reported that the AP2/EREBP gene $P U C H I$ is required for morphogenesis in the early lateral root primordium of Arabidopsis. However, this putative gene has not been well investigated in maize and needs further studies for better understanding of its importance in Striga resistance.

Through this GWAS, we were able to detect reliable QTLs associated with maize plant defense mechanisms under Striga infestation. The information provided in this study would serve as the starting point for functional gene studies to clarify the genetic mechanisms underlying Striga resistance in tropical maize inbred lines. After validation, the significant loci identified in this study could be targets for breeders in markerassisted selection to accelerate genetic enhancement of maize for Striga resistance in the tropics, particularly in the West and Central Africa sub-region.

\section{Conclusions and recommendations}

To the best of our knowledge, the present study is the first report of genome-wide association analysis for Striga resistance in maize. Twenty-four SNPs were significantly associated with Striga adaptive traits in maize. The candidate putative genes GRMZM2G060216, GRMZM2G057243 and GRMZM2G164743, on chromosomes 3, 9 and 10, respectively, could be invaluable for the development of Striga resistant maize genotypes in SSA. Further studies, using different mapping populations, are urgently needed to validate the markers identified in the present study so that marker-assisted breeding for Striga resistance in tropical maize could be a reality and widely adopted in SSA where Striga is endemic.

\section{Methods \\ Germplasm}

A total of 132 early maturing tropical white maize inbred lines (comprising one hundred and twenty-six early maturing $\mathrm{S}_{8}$ inbred lines, five standard inbred testers and one inbred check) with combined resistance to Striga hermonthica, and tolerance to drought stress developed in the IITA maize improvement program were used in this study. Out of the 132 inbred lines, 126 were second generation lines extracted from six $\mathrm{F}_{2}$ populations derived from bi-parental crosses (TZE COMP 5-W DT C7 x TZEI 56, TZE COMP 5-W DT C7 x TZEI 87, TZE COMP 5-W DT C7 x TZEI 18, TZE COMP 5-W DT C7 x TZEI 31, TZE COMP 5-W DT C7 x TZEI 2, TZE COMP 5-W DT C7 x TZEI 65), which involved crosses among a broad based Striga resistant population (TZE COMP 5-W DT C7) and elite inbred lines from TZE-W Pop $\times 1368$ STR (TZEI 87, TZEI 2), TZE-W Pop STR $C_{0}$ (TZEI 65, TZEI 18 and TZEI 56), and TZEW Pop x LD (TZEI 31). Of the five standard testers, inbreds TZEI 18, and TZEI 19 were derived from TZE-W Pop STR $C_{0}$, inbred TZEI 31 from TZE-W Pop x LD, inbred TZEI 7 from WEC STR and inbred TZdEI 352 from TZE-W Pop STR.

The broad based Striga resistant population TZE COMP 5-W DT C7 from which the inbred lines evaluated in this study were derived, had gone through $7 \mathrm{cy}$ cles of recurrent selection for improved Striga resistance. TZE COMP 5-W DT C7 was crossed to the inbred lines TZEI 65, TZEI 18, TZEI 31, TZEI 87, TZEI 2 and TZEI 56 selected for drought tolerance to improve the population for drought tolerance. Following the introgression of the drought tolerance genes into the population, a program was initiated to extract inbred lines with combined Striga resistance and drought tolerance using repeated self-pollination and selection for Striga resistance and drought tolerance. After eight cycles of inbreeding, the inbred lines were evaluated under drought and Striga infestation. Based on the results of the evaluations, the $S_{8}$ inbred lines used in the present study were selected.

\section{Phenotyping}

The inbred lines were phenotyped for key agronomic traits across two environments under artificial Striga infestation and two Striga-free environments at Mokwa, 
Nigeria $\left(9^{0} 18^{\prime} \mathrm{N}, 5^{0} 4^{\prime} \mathrm{E}, 457 \mathrm{~m}\right.$ altitude, $1100 \mathrm{~mm}$ annual rainfall) during the rainy seasons of 2017 and 2018. The experimental design was $11 \times 12$ alpha lattice with two replications. Each experimental unit consisted of $3 \mathrm{~m}$ single-row plots, with a row spacing of $0.75 \mathrm{~m}$ and intrarow spacing of $0.4 \mathrm{~m}$. The fields were injected with ethylene gas at about 10 days before planting, to stimulate suicidal germination of residual Striga seeds in the soil. The artificial Striga infestation at Mokwa was carried out as recommended by IITA-MIP [56]. Striga seeds collected from sorghum fields were stored for about 6 months to break seed dormancy and used for the infestation. Each hole in the Striga plot received about 5000 germinable seeds of Striga mixed with fine sand in the ratio 1:99. Fertilizer rate was reduced $(30 \mathrm{~kg} \mathrm{~N} / \mathrm{ha}, 30 \mathrm{~kg}$ each of $\mathrm{P}$ and $\mathrm{K}$ applied as NPK 15-15-15) and application was delayed till 3 weeks after planting to induce the production of strigolactones which stimulate good germination of the Striga seeds and the attachment of the Striga plants to the roots of host plants [57]. Under the artificial Striga infestation, data were collected on number of emerged Striga plants and host plant damage syndrome rating at 8 and 10 weeks after planting (WAP). The host plant damage syndrome rating was recorded on a scale of 1-9 $(1=$ normal plant growth, no visible symptoms, and $9=$ complete scorching of all leaves, causing premature death or collapse of host plant and no ear formation). Under both Striga-infested and Striga-free environments, data were collected on the inbred lines for ear aspect, number of ears per plant and grain yield.

\section{Phenotypic data analysis}

Analyses of variance (ANOVA) were performed across test environments for each experiment on plot mean basis for grain yield and other key agronomic traits with PROC GLM in SAS [58], using a RANDOM statement with TEST option. Location-year combinations were treated as environments. The IITA base index was used to identify Striga resistant and susceptible inbred lines under artificial Striga infestation [1]. The means of the selected traits were expressed in standard deviation units and the index scores were computed as: $I=((2 \times \mathrm{YLD})+$ EPP - (SDR8 + SDR10) - 0.5(ESP8 + ESP10)), where YLD = grain yield of the Striga-infested plots, EPP is the number of ears at harvest in the Striga infested plots, SDR8 and SDR10 were Striga damage syndrome ratings at 8 and 10 WAP, and ESP8 and ESP10 were number of emerged Striga plants at 8 and 10 WAP. Broad sense heritability $\left(\mathrm{H}^{2}\right)$ estimates were calculated from phenotypic variance $\left(\sigma_{p}^{2}\right)$ and the genotypic variance $\left(\sigma_{g}^{2}\right)$ [59]. Correlation analysis was done using the performance analytics package in $\mathrm{R}[60]$.

\section{Genotyping and quality control}

Samples of leaves were taken in the field at 2 weeks after planting. The DArT protocol was used for genomic DNA extraction (www.diversityarrays.com/files/DArT DNA_isolation.pdf). The quality and quantity of the DNA was ascertained by running the gDNA in a $1 \%$ agarose gel and measuring its concentration and purity in a NanoDrop 2000 spectrophotometer. The DNA samples were sent to the Integrated Genomic Service and Support (IGSS) genotyping platform, Nairobi, Kenya for genotyping. High-throughput genotyping was conducted in 96 plex DArTseq protocol as described previously [26]. Reads and tags found in each sequencing result were aligned to the Zea mays L. genome reference, version AGPV3 (B73 Ref-Gen v4 assembly) [61], resulting in a raw dataset of 47,440 markers. The 47,440 DArTseq markers were filtered to eliminate SNPs with missing rate greater than $10 \%$, heterozygosity greater than $20 \%$ and minor allele frequency (MAF) less than 5\%. SNPs with unknown or multiple chromosomes locations were also eliminated. After quality filtering, a total of 7224 DArTseq markers distributed across the 10 maize chromosomes were used for the population structure, phylogenetic analysis and GWAS analyses.

\section{Population structure, linkage disequilibrium and marker- trait association analyses}

An admixture model-based clustering method was used to infer population structure of the 132 genotypes using the software package STRUCTURE, version 2.3.4 [62]. The assumed number of subpopulations was simulated from $k=1$ to $k=10$ for an initial assessment of the most likely number of subpopulations; each $\mathrm{K}$ was run 10 times with 10,000 iterations of burn-in followed by 10 , 000 Markov chain Monte Carlo iterations and the ideal number of subpopulations $(K)$ was found by examining the optimal $\Delta K$ value [19] in STRUCTURE Harvester [63]. In the model-based method, membership coefficients ( $Q$ values) for each inbred line were estimated to have its memberships in multiple subgroups. Inbred lines with membership probabilities $\geq 0.70$ were assigned to the corresponding subgroup and lines with membership probabilities $<0.70$ were assigned to a mixed subgroup. Linkage disequilibrium was determined using the squared allele frequency correlations $R^{2}$ value from which the number of significant allele pairs $(P<0.01)$ was determined using 1000 permutations [64].. Association analysis between the SNPs and traits was performed using the mixed linear model (MLM) implemented in the GAPIT (Genetic Association and Prediction Integrated Tools) $\mathrm{R}$ package. The MLM adopted was proposed by $\mathrm{Yu}$ et al. [32] with each molecular marker considered a fixed effect and evaluated individually: $\mathrm{Y}=\mathrm{X}_{\beta}+\mathrm{W}_{\alpha}+\mathrm{Q}_{\mathrm{v}}+\mathrm{Z}_{\mathrm{u}}+\varepsilon$ where $Y$ is the 
observed vector of means; $\beta$ is the fixed effect vector $(p$ $\times 1$ ) other than molecular markers effects and population structure; $\alpha$ is the fixed effect vector of the molecular markers; $v$ is the fixed effect vector from the population structure; $u$ is the random effect vector from the polygenic background effect; $X, W$, and $Z$ are the incidence matrixes from the associated $\beta, \alpha, v$, and $u$ parameters; and $\varepsilon$ is the residual effect vector. MLM in comparison with other models for detecting marker/trait associations such as the general linear model (GLM), could reduce the false-positive associations by controlling both types I and II errors $[65,66]$. The Bonferroni correction showed a very stringent threshold. Consequently, a GWAS threshold of $-\log (\mathrm{p})=4$ was used to declare significant marker-trait associations, which was determined based on the Q-Q plots and distribution of $p$-values for all the traits $[22,35,67]$. To identify gene models for Striga resistance, the physical positions of the significant SNPs were compared with the MaizeGDB database according to version 4 (RefGen_v4) from the reference genome of the maize B73 inbred line, available at the MaizeGDB database. Zoom mapping was conducted on the chromosome where a significant SNP marker was identified and associated with a trait. The extent of local LD was evaluated for each selected significant SNP to determine the interval of each locus. The heatmap of regional LD was made with the LD heatmap package [68] for SNPs with a MAF greater than 0.05 within $500 \mathrm{~kb}$ downstream and upstream of the top associated SNP.

\section{Supplementary information}

Supplementary information accompanies this paper at https://doi.org/10. 1186/s12870-020-02360-0.

Additional file 1: Figure S1. Quality filtering of 44,470 markers among 132 maize inbred lines. Description of data: Quality filtering of 44,470 markers among 132 maize inbred lines that were used for population structure analysis and the GWAS.

Additional file 2: Table S1. Summary statistics of the 7224 filtered high-quality SNP markers. Summary statistics of the 7224 filtered highquality SNP markers obtained from the total 44,470 markers.

Additional file 3: Figure S2. Genome-wide and chromosome-wide linkage disequilibrium (LD) decay plot. LD decay plot estimated based on pairwise squared allele frequency correlation coefficients $\left(R^{2}\right)$ among 7224 SNPs distributed across the 10 maize chromosomes. The values on the $y$-axis represent the squared correlation coefficient $R^{2}$ and the $x$-axis represents the genetic distance in megabases $(\mathrm{mb})$.

\section{Abbreviations}

QTL: Quantitative trait locus; ANOVA: Analysis of variance; chr: Chromosome; bp: Base pair; Kb: Kilo base pair; SNP: Single nucleotide polymorphism; GWAS: Genome-wide association study; SSA: Sub-Saharan Africa; MAF: Minor allele frequency; DArTseq: Diversity array technology sequencing; IITA: International Institute of Tropical Agriculture; MAS: Marker-assisted selection; LGS: Low germination stimulant; WAP: Weeks after planting; LD: Linkage disequilibrium; amt: Ammonium transporter; EREBPs: Ethyleneresponsive element-binding proteins; DREBs: Dehydration responsive element binding proteins; MLM: Mixed linear model; GAPIT: Genetic association and prediction integrated tools; GLM: General linear model

\section{Acknowledgements}

This research was supported by the Bill and Melinda Gates Foundation [OPP1134248]. The authors also acknowledge the IITA maize program and Bioscience Center staff of ITA for technical assistance during the evaluation of field trials and DNA extraction, respectively.

\section{Authors' contributions}

BBA developed the inbred lines used in the study; BBA and SA conceived, designed and executed the experiments; BBA, MG, ALGO - funding acquisition; SA, PA and ALGO analyzed the data; BBA, ALGO, ROA supervised SA; SA drafted the manuscript; BBA, ALGO, ROA, PA, and MG critically reviewed the manuscript. All contributing authors agreed to the final version of the manuscript.

\section{Funding}

This research was conducted through the funding support from Bill and Melinda Gates Foundation under the Stress Tolerant Maize for Africa (STMA) Project of IITA. The funding body played no role in the design of the study and collection, analysis, and interpretation of data and in writing the manuscript. The Integrated Genotyping Service and Support (IGSS) platform grant (ref. number PJ-002507) of BecA-ILRI, Kenya supported the genotyping of the inbred lines.

\section{Availability of data and materials}

The DArTseq datasets used in the present study have been deposited at the IITA repository. DOI: https://doi.org/10.25502/h7k9-3s55/d. Link to CKAN: http://data.iita.org/dataset/genotypic-data-for-maize-inbred-lines-for-diversitystudies-and-gwas.

Ethics approval and consent to participate

Not applicable.

\section{Consent for publication}

Not applicable.

\section{Competing interests}

The authors declare that the research was conducted in the absence of any commercial or financial relationships that could be construed as a potential conflict of interest.

\section{Author details}

${ }^{1}$ International Institute of Tropical Agriculture (IITA), PMB 5320, Oyo Road, Ibadan, Nigeria. ${ }^{2}$ Department of Crop Production and Protection, Obafemi Awolowo University, lle-lfe, Nigeria.

Received: 24 October 2019 Accepted: 24 March 2020

Published online: 11 May 2020

\section{References}

1. Badu-Apraku B, Fakorede MAB. Advances in genetic enhancement of early and extra-early maize for Sub-Saharan Africa. Switzerland: Springer; 2017.

2. Ransom JK. Long term approaches for the control of Striga in cereals: field management. Crop Prot. 2000;9:759-63.

3. Lagoke STO. Pan African Striga Control Network. In: Proceedings of the integrated Pest management communications workshop: eastern and southern Africa. Nairobi: ICIPE; 1998. p. 65-9.

4. Khan ZR, Pickett JA, Wadhams LJ, Hassanali A, Midega CAO. Combined control of Striga hermonthica and stemborers by maize Desmodium spp. intercrops. Crop Prot. 2006;25:989-95.

5. Ejeta G. Breeding for Striga resistance in sorghum: exploitation of an intricate host parasite biology. Crop Sci. 2007;47:216-27.

6. Atera E, Itoh K. Evaluation of ecologies and severity of Striga weed on rice in sub-Saharan Africa. Agric Biol J N Am. 2011;2:752-60.

7. Gurney AL, Press MC, Ransom JK. The parasitic angiosperm Striga hermonthica can reduce photosynthesis of its sorghum and corn hosts in the field. J Exp Bot. 1995;46:1817-23.

8. Akaogu IC, Badu-Apraku B, Adetimirin VO. Combining ability and performance of extra-early maturing yellow maize inbreds in hybrid 
combinations under drought and rain-fed conditions. J Agric Sci. 2017;155: 1520-40.

9. Liu H, Yan J. Crop genome-wide association study: a harvest of biological relevance. The Plant J. 2019;97:8-18,

10. Runo S, Kuria EK. Habits of a highly successful cereal killer, Striga. PLoS Pathog. 2018;14(1):e1006731.

11. Amusan IO. Mechanisms and quantitative trait loci for Striga hermonthica resistance in maize (Zea mays $\mathrm{L}$.) inbred line. PhD thesis at Purdue University; 2010.

12. Gobena D, Shimelis M, Rich PJ, Ruyter-spira C, Bouwmeester H, Kanuganti S. Mutation in sorghum LOW GERMINATION STIMULANT 1 alters strigolactones and causes Striga resistance. Proc Natl Acad Sci. 2017;114:4471-6.

13. Sun Z, Hans J, Walter MH, Matusova R, Beekwilder J, Verstappen FW, et al. Cloning and characterisation of a maize carotenoid cleavage dioxygenase (ZmCCD1) and its involvement in the biosynthesis of apocarotenoids with various roles in mutualistic and parasitic interactions. Planta. 2008;228:789801.

14. Aly R, Dubey NK, Yahyaa M, Abu-Nassar J, Ibdah M. Gene silencing of CCD7 and CCD8 in Phelipanche aegyptiaca by tobacco rattle virus system retarded the parasite development on the host. Plant Signal Behav. 2014;9(8):e29376.

15. Liu Q, Zhang Y, Matusova R, Charnikhova T, Amini M, Jamil M, et al. Striga hermonthica MAX2 restores branching but not the very low Fluence response in the Arabidopsis thaliana max2 mutant. New Phytol. 2014;202:2.

16. MIP. Maize Improvement Program, Archival Report, 1988-1992 - Part I. Maize population improvement. Ibadan: Crop Improvement Division, IITA; 1996.

17. Menkir A, Kling JG. Response to recurrent selection for resistance to Striga hermonthica (Del.) Benth in a tropical maize population. Crop Sci. 2007;47: 674-84.

18. Badu-Apraku B, Menkir A, Ajala SO, Akinwale RO, Oyekunle M, Obeng-Antwi K. Performance of tropical early-maturing maize cultivars in multiple stress environments. Can J Plant Sci. 2010a:90:1-22.

19. Evanno G, Regnaut $\mathrm{S}$, Goudet J. Detecting the number of clusters of individuals using the software STRUCTURE: a simulation study. Mol Ecol. 2005;14:2611-20

20. Badu-Apraku B, Akinwale RO, Fakorede MAB. Selection of early maturing maize inbred lines for hybrid production using multiple traits under Strigainfested and Striga-free environments. Maydica. 2010b;55:261-74.

21. Akinwale RO, Badu-Apraku B, Fakorede MAB, Vroh-Bi I. Heterotic grouping of tropical early-maturing maize inbred lines based on combining ability in Striga-infested and Striga-free environments and the use of SSR markers for genotyping. Field Crop Res. 2014;156:48-62.

22. Sukumaran S, Reynolds MP, Sansaloni C. Genome-wide association analyses identify QTL hotspots for yield and component traits in durum wheat grown under yield potential, drought, and heat stress environments. Front Plant Sci. 2018;9:81.

23. Kuki MC, Scapim CA, Rossi ES, Mangolin CA, ATD J, RJB P. Genome wide association study for gray leaf spot resistance in tropical maize core. PLoS One. 2018:13(6):e0199539.

24. Yuan Y, Cairns JE, Babu R, Gowda M, Makumbi D, Magorokosho C, et al. Genome-wide association mapping and genomic prediction analyses reveal the genetic architecture of grain yield and flowering time under drought and heat stress conditions in maize. Front Plant Sci. 2019:9:1919.

25. Badu-Apraku B, Akinwale RO, Oyekunle M. Efficiency of secondary traits in selecting for improved grain yield in extra-early maize under Striga-infested and Striga-free environments. Plant Breed. 2014;133(3):373-80.

26. Adu GB, Badu-Apraku B, Akromah R, Garcia-Oliveira AL, Awuku FJ, Gedil M. Genetic diversity and population structure of early-maturing tropical maize inbred lines using SNP markers. PLoS One. 2019;14(4):e0214810.

27. Simko I, Eujayl I, van Hintum TJL. Empirical evaluation of DArT, SNP, and SSR marker systems for genotyping, clustering, and assigning sugar beet hybrid varieties into populations. Plant Sci. 2012;184:54-62.

28. Zhang X, Zhang H, Li L, Lan H, Ren Z, Liu D, et al. Characterizing the population structure and genetic diversity of maize breeding germplasm in Southwest China using genome-wide SNP markers. BMC Genomics. 2016;17(1):1-16.

29. Yan J, Shah T. Warburton ML, Buckler ES, McMullen MD, Crouch J. Genetic characterization and linkage disequilibrium estimation of a global maize collection using SNP markers. PLoS One. 2009:4(12):e8451.

30. Azmach G, Menkir A, Spillane C, Gedil M. Genetic loci controlling carotenoid biosynthesis in diverse tropical maize lines. G3-Genes Genom Genet. 2018; 8(3):1049. https://doi.org/10.1534/g3.117.300511.
31. Schnable PS, Ware D, Fulton RS, Stein JC, Wei F, Pasternak S, et al. The B73 maize genome: complexity, diversity, and dynamics. Science. 2009;326: $1112-5$.

32. Yu J, Pressoir G, Briggs WH, Bi IV, Yamasaki M, Doebley JF, et al. A unified mixed-model method for association mapping that accounts for multiple levels of relatedness. Nat Genet. 2006;38(2):203-8.

33. Cui C, Mei H, Liu Y, Zhang H, Zheng Y. Genetic diversity, population structure, and linkage disequilibrium of an association-mapping panel revealed by genome-wide SNP markers in sesame. Front Plant Sci. 2017;8: 1189.

34. Campa A, Murube E, Ferreira JJ. Genetic diversity, population structure, and linkage disequilibrium in a Spanish common bean diversity panel revealed through genotyping-by-sequencing. Genes. 2018;9:518.

35. Mogga M, Sibiya J, Shimelis H, Lamo J, Yao N. Diversity analysis and genome-wide association studies of grain shape and eating quality traits in rice (Oryza sativa L.) using DArT markers. PLoS One. 2018;3(6):e0198012.

36. Maldonado C, Mora F, Scapim CA, Coan M. Genome-wide haplotype-based association analysis of key traits of plant lodging and architecture of maize identifies major determinants for leaf angle: hapLA4. PLoS One. 2019;14(3): e0212925.

37. Yu J, Buckler ES. Genetic association mapping and genome organization of maize. Curr Opin Biotechnol. 2006;17:155-60.

38. Mwadzingeni L, Shimelis H, Rees DJG, Tsilo TJ. Genome-wide association analysis of agronomic traits in wheat under drought-stressed and nonstressed conditions. PLoS One. 2017;12(2):e0171692.

39. Chang M, Lynn DG. The haustorium and the chemistry of host recognition in parasitic angiosperms. J Chem Ecol. 1986;12:561-79.

40. Xie X, Yoneyama K, Yoneyama K. The strigolactone story. Annu Rev Phytopathol. 2010;48:93-117.

41. Gu R, Duan F, An X, Zhang F, von Wirén N, Yuan L. Characterization of AMTmediated high-affinity ammonium uptake in roots of maize (Zea mays L.). Plant Cell Physiol. 2013:54:1515-24.

42. Koegel S, Ait Lahmidi N, Arnould C, Chatagnier O, Walder F, Ineichen K, et al. The family of ammonium transporters (AMT) in Sorghum bicolor: two AMT members are induced locally, but not systemically in roots colonized by arbuscular mycorrhizal fungi. New Phytol. 2013;198:853-65.

43. Dechorgnat J, Francis KL, Dhugga KS, Rafalski JA, Tyerman SD, Kaiser BN. Tissue and nitrogen-linked expression profiles of ammonium and nitrate transporters in maize. BMC Plant Biol. 2019;19(1):206.

44. Kamara AY, Ekeleme F, Omoigui L, Menkir A, Chikoye D, Dugje IY, et al. Influence of nitrogen fertilization on the performance of early and late maturing maize varieties under natural infestation with Striga hermonthica (Del.) Benth. Arch Agron Soil Sci. 2009;55(2):125-45.

45. Tian F, Bradbury PJ, Brown PJ, Hung H, Sun Q, Flint-Garcia S, et al. Genomewide association study of leaf architechure in the maize nested association mapping population. Nat Genet. 2011;43:2.

46. Watling JR, Press MC. Impacts of infection by parasitic angiosperms on host photosynthesis. Plant Biol. 2001;3:244-50.

47. van AA. The influence of time and severity of Striga infection on the Sorghum bicolor - Striga hermonthica association. Wageningen: PhD thesis, Wageningen University; 2006. p. 154.

48. Graves JD, Press MC, Stewart GR. Growth and carbon allocation in Pennisetum typhoides infected with the parasitic angiosperm Striga hermonthica. Plant Cell Environ. 1990;13:367-73.

49. Graves JD, Press MC, Smith S, Stewart GR. The carbon canopy economy of the association between cowpea and the parasitic angiosperm Striga gesnerioides. Plant Cell Environ. 1992;15:283-8.

50. Smith LH, Keys AJ, Evans MCW. Striga hermonthica decreases photosynthesis in Zea mays through effects on leaf cell structure. J Exp Bot. 1995;46(288):759-65.

51. Lu Y, Yao J. Chloroplasts at the crossroad of photosynthesis, pathogen infection and plant defense. Int J Mol Sci. 2018;19(12):3900.

52. Licausi F, Ohme-Takagi M, Perata P. APETALA2/ethylene responsive factor (AP2/ERF) transcription factors: mediators of stress responses and developmental programs. New Phytol. 2013;199:639-49.

53. Jisha V, Dampanaboina L, Vadassery J, Mithofer A, Kappara S, Ramanan R. Overexpression of an AP2/ERF type transcription factor OsEREBP1 confers biotic and abiotic stress tolerance in rice. PLoS One. 2015;10:e0127831.

54. Li B, Li Q, Mao X, Li A, Wang J, Chang X, et al. Two novel AP2/EREBP transcription factor genes TaPARG have pleiotropic functions on plant architecture and yield-related traits in common wheat. Front Plant Sci. 2016; 7:1191. 
55. Hirota A, Kato T, Fukaki H, Aida M, Tasaka M. The auxin-regulated AP2/EREBP gene PUCHI is required for morphogenesis in the early lateral root primordium of Arabidopsis. Plant Cell. 2007;19(7):2156-68.

56. Kim SK. Breeding maize for Striga tolerance and the development of a field infestation technique. In: Kim SK, editor. Combating Striga in Africa. Proceedings of the Workshop by IITA, ICRISAT and IDRC, Aug. 22-24, 1988. Ibadan: IITA; 1991. p. 96-108.

57. Kim SK, Winslow MD. Progress in breeding maize for Striga-tolerance/ resistance at IITA 1991. In: Ransom JK, editor. Proceeding of 5th Intl. Symp. Parasitic Weeds, Nairobi. Ibadan: ITA; 1991. p. 494-9.

58. SAS Institute Inc. Statistical analysis software (SAS) user's guide. Cany: SAS Inst; 2013.

59. Hallauer AR, Carena MJ, Miranda Filho JD. Quantitative genetics in maize breeding. New York: Springer; 2010

60. R Core Team R. A Language and Environment for Statistical Computing. Vienna: R Foundation for Statistical Computing; 2015. https:/www.R-project.org.

61. Jiao Y, Peluso P, Shi J, Tiffany L, Stitzer MC, Wang B, et al. Improved maize reference genome with single-molecule technologies. Nature. 2017;546:524-7.

62. Pritchard JK, Stephens M, Donnelly P. Inference of population structure using multilocus genotype data. Genetics. 2000;155:945-59.

63. Earl DA, von Holdt BM. Structure Harvester: a website and program for visualizing STRUCTURE output and implementing the Evanno method. Conserv Genet Resour. 2012:4:359-61.

64. Bradbury PJ, Zhang Z, Kroon DE, Casstevens TM, Ramdoss Y, Buckler ES. TASSEL: software for association mapping of complex traits in diverse samples. Bioinformatics. 2007;23:2633-5.

65. Pasam RK, Sharma R, Malosetti M, Eeuwijk FAV, Haseneyer G, Kilian B, et al. Genome-wide association studies for agronomical traits in a worldwide spring barley collection. BMC Plant Biol. 2012;12:16.

66. Ahmad MA, Khan SH, Khan AS, Kazi AM, Basra SMA. Identification of QTLs for drought tolerance traits on wheat chromosome $2 \mathrm{~A}$ using association mapping. Int J Agric Biol. 2014;16:862-70.

67. Gao L, Turner MK, Chao S, Kolmer J, Anderson JA. Genome wide association study of seedling and adult plant leaf rust resistance in elite spring wheat breeding lines. PLoS One. 2016;11(2):e0148671.

68. Shin S, Graham J, McNeney B. LDheatmap: an R function for graphical display of pairwise linkage disequilibria between single nucleotide polymorphisms. J Stat Softw. 2006;16:1-9. https://doi.org/10.18637/jss.v016.c03.

\section{Publisher's Note}

Springer Nature remains neutral with regard to jurisdictional claims in published maps and institutional affiliations.

Ready to submit your research? Choose BMC and benefit from:

- fast, convenient online submission

- thorough peer review by experienced researchers in your field

- rapid publication on acceptance

- support for research data, including large and complex data types

- gold Open Access which fosters wider collaboration and increased citations

- maximum visibility for your research: over $100 \mathrm{M}$ website views per year

At $\mathrm{BMC}$, research is always in progress.

Learn more biomedcentral.com/submissions 